\title{
Integration of transport-based models for phyllotaxis and midvein formation
}

\author{
Emmanuelle M. Bayer, ${ }^{1,4}$ Richard S. Smith, ${ }^{1,4}$ Therese Mandel, ${ }^{1}$ Naomi Nakayama, ${ }^{1}$ Michael Sauer, ${ }^{2,5}$ \\ Przemyslaw Prusinkiewicz, ${ }^{3}$ and Cris Kuhlemeier ${ }^{1,6}$ \\ ${ }^{1}$ Institute of Plant Sciences, University of Bern, CH-3013 Bern, Switzerland; ${ }^{2}$ VIB, Department of Plant Systems Biology, \\ Universiteit Gent, B- 9052 Gent, Belgium; ${ }^{3}$ Department of Computer Science, University of Calgary, Calgary, \\ Alberta T2N 1N4, Canada
}

The plant hormone auxin mediates developmental patterning by a mechanism that is based on active transport. In the shoot apical meristem, auxin gradients are thought to be set up through a feedback loop between auxin and the activity and polar localization of its transporter, the PIN1 protein. Two distinct molecular mechanisms for the subcellular polarization of PIN1 have been proposed. For leaf positioning (phyllotaxis), an "up-the-gradient" PIN1 polarization mechanism has been proposed, whereas the formation of vascular strands is thought to proceed by "with-the-flux" PIN1 polarization. These patterning mechanisms intersect during the initiation of the midvein, which raises the question of how two different PIN1 polarization mechanisms may work together. Our detailed analysis of PIN1 polarization during midvein initiation suggests that both mechanisms for PIN1 polarization operate simultaneously. Computer simulations of the resulting dual polarization model are able to reproduce the dynamics of observed PIN1 localization. In addition, the appearance of high auxin concentration in our simulations throughout the initiation of the midvein is consistent with experimental observation and offers an explanation for a long-standing criticism of the canalization hypothesis; namely, how both high flux and high concentration can occur simultaneously in emerging veins.

[Keywords: Auxin; transport; PIN1; phyllotaxis; vein; computer simulation]

Supplemental material is available at http://www.genesdev.org.

Received July 16, 2008; revised version accepted December 17, 2008.

Phyllotaxis, the regular arrangement of lateral organs around a plant stem, is an example of developmental pattern formation and organogenesis. Leaves (or flowers) are initiated at the shoot apical meristem, in a band of cells derived from the stem cells at the summit of the meristem. The process of leaf initiation is closely linked to the formation of the midvein, the strand of vascular tissue in the center of the leaf primordium that is specified even before the primordium begins to bulge out of the surface of the meristem. Theoretical approaches have suggested a variety of mechanisms for the regulation of phyllotaxis and vein formation (Hellendoorn and Lindenmayer 1974; Green 1980; Mitchison 1980; Meinhardt 1982; Couder et al. 2002; Runions et al. 2005; Jönsson et al. 2006; Smith et al. 2006). Simulations confirmed that these mechanisms can produce the observed patterns, but until recently the lack of experi-

\footnotetext{
${ }^{4}$ These authors contributed equally to this work.

${ }^{5}$ Present address: Centro Nacional de Biotecnología, CSIC, 28049 Madrid, Spain.

${ }^{6}$ Corresponding author.

E-MAIL cris.kuhlemeier@ips.unibe.ch; FAX 41-31-332-20-59.

Article is online at http://www.genesdev.org/cgi/doi/10.1101/gad.497009.
}

mental data has made it hard to judge their biological plausibility.

According to current data (Benkova et al. 2003; Reinhardt et al. 2003b; Heisler et al. 2005; Scarpella et al. 2006), an auxin maximum in the L1 surface layer of the meristem is the earliest marker of a new leaf primordium. This maximum arises concomitantly with the subcellular localization of the auxin transport protein PIN1 toward the auxin convergence point at the center of the incipient primordium (Reinhardt et al. 2003b; Heisler et al. 2005; de Reuille et al. 2006). In experimental manipulations, the application of auxin at the peripheral zone of the meristem is sufficient to induce organ formation (Reinhardt et al. 2000, 2003b), whereas the inhibition of auxin transport has been shown to block organ formation and the establishment of the convergence point (Reinhardt et al. 2000, 2003b; Smith et al. 2006). Together these data suggest that leaf initiation is caused by high intracellular auxin concentration that results from directional auxin transport toward the convergence point.

As in phyllotaxis, the earliest molecular markers for midvein formation are the expression of PIN1 and the auxin activity reporter DR5 (Scarpella et al. 2006). From 
the convergence point, a strand of cells with high DR5 and high PIN1 expression extends into the subepidermal layers and will subsequently express early markers of the vasculature, such as the homeobox transcription factor ATHB8 (Baima et al. 1995; Scarpella et al. 2004, 2006). The ectopic application of auxin induces the formation of additional veins (Sachs 1981; Scarpella et al. 2006), whereas transport inhibition seriously distorts vein pattern formation (Mattsson et al. 1999, 2003).

The above data suggest that both the phyllotaxis and vein patterning are based on directional transport of auxin. The key question is, what mechanism or mechanisms determine the transport direction (cell polarity) in each case. In the absence of explicit molecular data, mechanisms based on a feedback between auxin concentration, flux, and cell polarization have been inferred from indirect experimental evidence and computer simulation studies (for review, see Kramer 2008). To explain phyllotaxis, Jönsson et al. (2006) and Smith et al. (2006) proposed that the auxin efflux carrier PIN1 polarly localizes in the plasma membrane toward cells of higher auxin concentration ("up-the-gradient" polarization). Small auxin maxima are amplified, resulting in distinct auxin peaks that activate the auxin receptor and auxindependent transcription factors, and thus trigger leaf development. To explain the formation of veins, Sachs (1969, 1981) proposed the canalization model, subsequently supported with simulations by Mitchison (1980, 1981). According to this model, a cell's ability to transport auxin increases with auxin flux. As auxin flows through a plant tissue, slight preferences for a particular path are thus reinforced by flux-based feedback. This process leads to the formation of high-flux paths, precursors of veins, in much the same way as water running down soft terrain would canalize into rivers. In molecular terms, the direction of the flux controls the polar localization of the auxin transporter PIN1, which in turn enhances the flux in that direction ("with-the-flux" polarization).

The up-the-gradient and with-the-flux models suggest separate mechanisms for polarizing PIN1 in phyllotactic patterning versus vein initiation. However, the processes that establish the position of the leaf primordium take place in the same region of the meristem and occur at the same time as the processes that initiate the midvein. The overlap of these processes is further evident in the continuous auxin flow first toward, then away from, the convergence point. This raises the question of how the patterning mechanisms proposed for phyllotaxis and midvein formation can be reconciled in a unified model.

Addressing this question, Merks et al. (2007) proposed a model of vein formation based on the same up-thegradient mechanism used for the phyllotaxis models (Jönsson et al. 2006; Smith et al. 2006). In the model by Merks et al., the peak of auxin concentration that causes primodium initiation in the L1 subsequently moves as a traveling wave into the internal tissue, leaving a trail of polarized PINs in its wake. Their model predicts a switch in PIN polarity of the cells at the leaf tip and thus requires a reduced auxin concentration at the tip relative to the cells in inner tissue immediately below. In contrast, Scarpella et al. (2006) observed that during early vein formation this peak does not diminish, but, in fact, it gets brighter as early leaf development proceeds, likely enhanced by the expression of auxin biosynthesis genes at this point (Zhao 2008). This is very difficult to reconcile with a model requiring that this peak move. The model by Merks et al. (2007) is also difficult to reconcile with the experiments of Sachs $(1969,1981)$ that suggest there must be some flux-based component to venation patterning, a property that is entirely missing from this model.

Interestingly, the opposite approach was taken by Stoma et al. (2008), who proposed to explain phyllotaxis by a with-the-flux mechanism. In this model, the flux toward pre-existing primordia causes a shallow auxin maximum at a distance from pre-existing primordia. This auxin maximum causes primordium specification and a strong flux into internal tissue. This flux causes a strong local auxin minimum at the surface, which in turn creates the PIN1 convergence point. Thus, the model predicts that the convergence points of PIN1 expression that mark incipient primordia are accompanied by a drop in auxin levels. This is difficult to reconcile with the punctate expression pattern of strongly up-regulated DR5 that occurs concomitantly with these PIN1 convergence points (Heisler et al. 2005; Smith et al. 2006). The model also makes the same prediction as classical canalization models (Mitchison 1980; Rolland-Lagan and Prusinkiewicz 2005) in the formation of the midvein. These models predict high flux but low auxin concentration in initiating veins, which is contrary to experimental observations (Scarpella et al. 2006). The presence of auxin importers has been proposed as a solution to this problem (Kramer 2004; Dupuy et al. 2008).

An attractive attribute of these proposals is that both postulate a single mechanism for both phyllotaxis and vein formation. The key question of the biological plausibility of these models remains open, however. In order to answer this question, we acquired detailed experimental data on the dynamic localization of PIN1 proteins during leaf initiation and midvein formation. On this basis, we propose a patterning model that integrates the up-the-gradient and with-the-flux polarization mechanisms by assuming that both mechanisms operate concurrently. In contrast to the previous models, our dualpolarization model is consistent with all experimental data available to date.

\section{Results}

\section{Tomato as a model system}

The expression pattern of PIN1 during phyllotactic patterning and early stages of vein formation has been observed previously and analyzed in apices of Arabidopsis (Reinhardt et al. 2003a; Heisler et al. 2005; de Reuille et al. 2006; Scarpella et al. 2006). However, in order to obtain high-resolution images of PIN1 expression in the vegetative shoot apical meristem, we turned to tomato. Compared with Arabidopsis, the nonrosette plant tomato 
has a larger and more accessible vegetative meristem, which facilitates micromanipulation studies as well as live imaging by confocal microscopy. Our aim was to provide a detailed analysis of the dynamics of PIN1 polarization in both the L1 layer and inner tissues, spanning the interval from specification of the incipient primordium to the beginning of primordium bulging.

PIN1 localization data were acquired with an antibody raised against the tomato PIN1 homolog and a transgenic line expressing an Arabidopsis PIN1-GFP construct under its own promoter (AtPIN1:GFP). Tomato PIN1 and AtPIN1:GFP showed undistinguishable localization patterns in vegetative tomato apices (Supplemental Fig. S1). In vegetative tomato apices, PIN1 was expressed in the L1 surface layer of the shoot apical meristem, where it localized at the anticlinal sides of the cells oriented toward the meristem summit (Fig. 1A,B). At the flank of the meristem, at the sites of incipient primordia, a strong signal was also detected in inner tissues, corresponding to the initiating midvein (Fig. 1A,D). In young bulging leaf primordia, PIN1 was strongly expressed in the developing vasculature (Fig. 1 A,C,D), where the polarization was primarily basal (Fig. 1C). PIN1 was also present in the epidermis, with an orientation directed toward the tip of the young organ (Fig. 1B). Overall, the strongest expression was found in domains subtending sites of incipient and young bulging primordia in the L1 and in emerging veins. Below the shoot apex, in the stem, PIN1 was oriented acropetally in the epidermis and basally in the vasculature (Supplemental Fig. S2). Thus, the overall patterns of expression and polarity of PIN1 in tomato vegetative apices closely resemble PIN1 localization in Arabidopsis (Reinhardt et al. 2003b; Heisler et al. 2005; de Reuille et al. 2006).

\section{I2 is not specified in tomato vegetative meristems}

The specification of an incipient organ primordium begins with the establishment of a convergence point in the L1. This convergence point is characterized by the polarization of PIN1 toward the center of the future primordium, establishing an auxin maximum (Reinhardt et al. 2003b; Heisler et al. 2005; de Reuille et al. 2006). In Arabidopsis, PIN1 convergence points marking incipient primordia can be seen as early as the I3 stage (I1, I2, etc. are the incipient primordia numbered in the order of appearance). In tomato, however, PIN1 convergence points at the meristem surface were only visible at the I1 position (Fig. 1E), with an approximate divergence angle of $137^{\circ}$. PIN1 polarity at I2 was mainly directed toward the convergence point at I1, which was established shortly after P1 bulging (Supplemental Fig. S3).

\section{The developing midvein displays a complex pattern of contrasting PIN1 polarities}

The PIN1 expression pattern below the convergence point was characterized by the establishment of a V-shaped domain, with PIN1 polarization gradually changing from lateral through oblique to basal between cells increas-
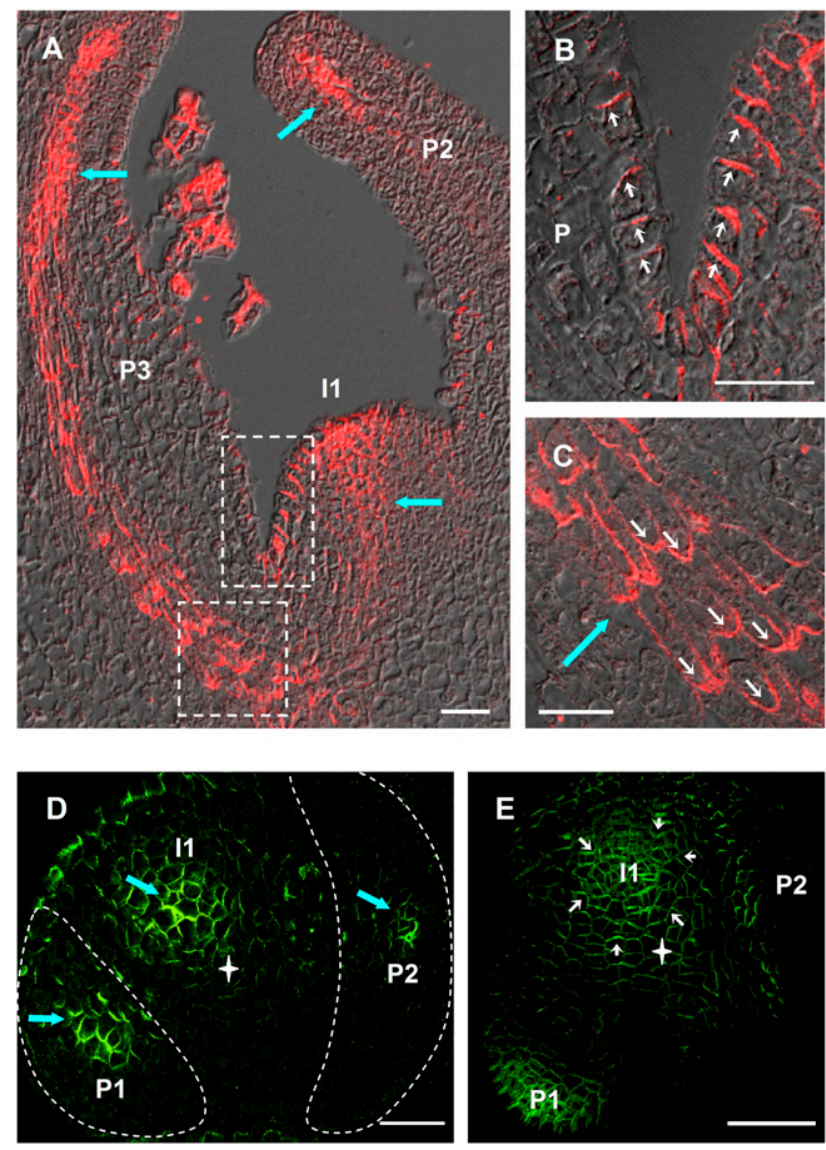

Figure 1. PIN1 expression pattern in vegetative apices of wildtype tomato. $(A-C)$ Longitudinal sections through a wild-type tomato vegetative shoot apical meristem. (A) Overview. $(B)$ Closeup of L1 layer at meristem-primordium junction (top white frame in $A$ ). Note the polarization toward the tip of the meristem as well as toward the tip of the primordium. $(C)$ Closeup of developing vein tissue (bottom panel in A). Note the predominantly basal polarization. $(D)$ Transversal section $40 \mu \mathrm{m}$ below shoot apical meristem summit. The outlines of bulging primordia have been highlighted in white for clarity. (E) Top view of a vegetative meristem. To access the meristem, $\mathrm{P} 2$ was removed. In $D$ and $E$, no PIN1 signal is visible at the presumptive I2 position. White star indicates meristem center. Thick blue arrows indicate vasculature. White arrows indicate PIN1 polarization. (P1, P2, P3) Bulging leaf primordia; (I1) incipient primordium. Bars, $25 \mu \mathrm{m}$. (A$D)$ Tomato PIN1 protein. Immunolocalization on wax sections. (E) Arabidopsis PIN1:GFP fusion protein. Maximum projection of confocal optical sections.

ingly close to the future vein (Fig. 2A, red, yellow, and white arrows, respectively). In the early P1 stage, the basal and lateral orientations became more pronounced, especially toward the tip of the initiating vein, whereas oblique polarization was less frequent (Fig. 2B). At later stages (Fig. 2C), the PIN1 expression domain became restricted to narrow cell files, and only two distinct polarizations for PIN1 were observed. In the center of the PIN1 expression domain, PIN1 was found to polarize basally (Fig. 2C), suggesting an auxin flux directed downward. At the edges of the PIN1 expression domain, PIN1 

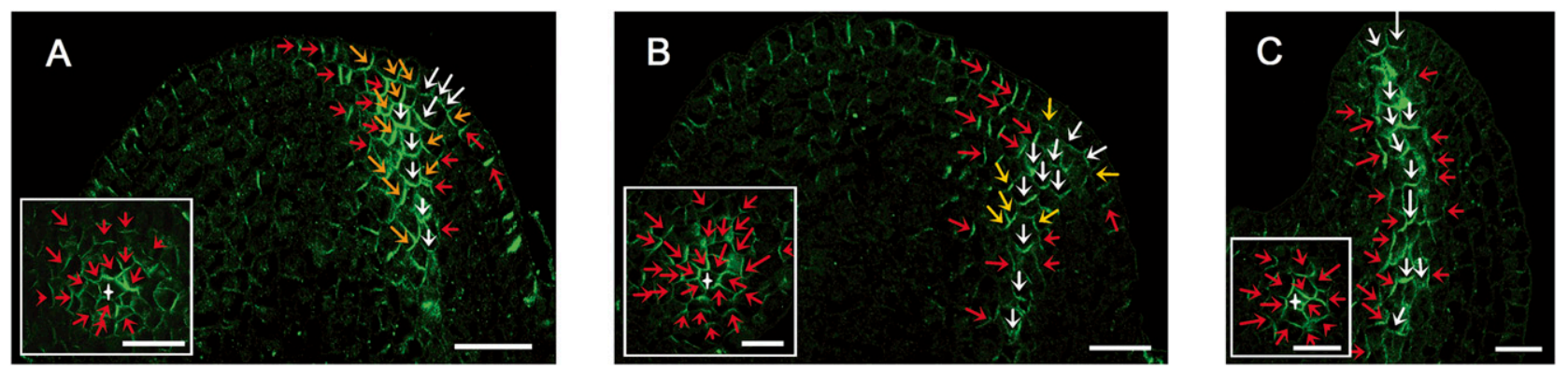

Figure 2. Progressive establishment of basal and lateral PIN1 polarization during midvein formation. PIN1 immunolocalization on vegetative tomato meristem sections, visualized by confocal imaging. Longitudinal and transversal sections (insets) through an incipient primordium $(A)$, bulging leaf primordium at early P1 stage $(B)$, and primordium at P2 stage $(C)$. PIN1 polarization is indicated by arrows (red for lateral toward the future midvein, yellow for oblique, and white for basal). White star indicates midvein. Bars, $20 \mu \mathrm{m}$.

was found to polarize laterally (Fig. 2C) toward the midvein, suggesting auxin drainage from the surrounding areas. The emerging midveins of bulging sepal and leaflet primordia displayed comparable PIN1 localizations (Supplemental Fig. S4). Similar expression and polarization patterns were also observed in tomato apices expressing AtPIN1:GFP (Supplemental Fig. S5), although precise polarization events and especially lateral polarization were more difficult to assess by live confocal imaging than immunolocalization on meristem sections. Analogous lateral and basal polarizations could be observed in Arabidopsis (Fig. 5C, below; Supplemental Fig. S6). Lateral PIN1 polarization toward the developing vasculature was also observed in higher-order veins in young leaves of tomato and Arabidopsis (Supplemental Fig. S7).

Although previous work on Arabidopsis has described PIN1 polarization in initiating midvein as essentially basal, our data point out to a more complex polarization pattern. Strikingly, we found that adjacent cells can have contrasting, lateral, or basal PIN1 polarizations, and the establishment of these polarizations in emerging midveins is gradual.

\section{Molecular basis of the model}

The new data presented here, together with the data collected previously, show that the process of leaf positioning begins with the convergent localization of PIN1 proteins and an auxin maximum at Il. While auxin in this convergence point continues to accumulate, the center L1 cells begin to display basal PIN1 polarization. PIN1 turns on in the internal layers in a triangular expression domain that gradually resolves into a narrow canal with high auxin concentration and basal PIN1 polarization in the center and lateral polarization in the adjacent cells. Thus it appears that cells can change their polarization from convergent (anticlinal) to basal in the L1, and adjacent cells in inner tissue that were previously uncommitted can adopt lateral or basal polarities.

We explored different models to capture these dynamics of auxin distribution and PIN1 expression and polarity. Both up-the-gradient and with-the-flux models seem plausible based on experimental data and simulations. However, we found that a single mechanism was never fully adequate, and neither was a model with purely up- the-gradient polarization in the L1 and with-the-flux polarization in inner tissues. Therefore, we propose an alternative model that integrates the up-the-gradient and with-the-flux polarization mechanisms by assuming that both mechanisms operate concurrently in both cell types. Each cell of the meristem can dynamically choose the dominant mechanisms, with the choice depending on the auxin concentration. As the basis for the model equations, we formulated the following assumptions:

1. PIN1 is induced by auxin. This hypothesis is well supported by experimental evidence (Heisler et al. 2005; Vieten et al. 2005; Scarpella et al. 2006).

2. Midvein formation is initiated by an increase in auxin concentration. This assumption is based on the observation that both the early markers PIN1 and DR5 and later markers such as ATHB8 are auxin-induced genes (Baima et al. 1995; Scarpella et al. 2004; Heisler et al. 2005). In line with a large body of published work (Uggla et al. 1996; Avsian-Kretchmer et al. 2002; Mattsson et al. 2003; Reinhardt et al. 2003b; Kang and Dengler 2004; Scarpella et al. 2004, 2006; Heisler et al. 2005; de Reuille et al. 2006; Smith et al. 2006), we use DR5 and PIN1 as indirect, qualitative measures of auxin levels. Based on available data, we assume that the auxin level in initiating veins is high rather than low when compared with surrounding tissues. This is in contrast to the classical canalization model (Mitchison 1980, 1981; Sachs 1981) that predicts low auxin concentration in the developing vein.

3. The cells in the L1 have a different identity from the cells in the inner tissues (Vroemen et al. 1996; SavaldiGoldstein et al. 2007). In particular:

a. Communication between L1 and inner tissues is reduced (Rinne and van der Schoot 1998; Bainbridge et al. 2008).

b. Auxin-independent synthesis of PIN1 is negligible in the inner tissues, but occurs in the L1. This assumption is based on the observation that all L1 cells contain PIN1, whereas in the inner tissues there are cells virtually devoid of it (Fig. 2).

Assumptions 1-3 have considerable support from experimental work. However, the question remains of how 
PIN1 is polarized. After trying several options, we arrived at the following hypotheses:

4. The up-the-gradient and with-the-flux polarization mechanisms act simultaneously, in varying proportions, within individual cells. The inspiration for this assumption comes from careful inspection of the cells at the convergence point, where cells of the L1 change polarity from anticlinal to basal (Fig. 2A).

5. The transition from up-the-gradient to with-the-flux polarization depends on auxin concentration. Inspection of longitudinal sections strongly shows that both PIN1 and DR5 expression in the convergence point and along the developing vein are considerably higher than in the surrounding cells. This suggests increasing auxin concentration as a plausible factor controlling the transition from up-the-gradient to with-the-flux polarization.

\section{Description of the model}

The resulting model schematically represents a longitudinal section through the shoot apex as a rectangular grid of cells. A similar representation was used by Mitchison (1980, 1981) and Rolland-Lagan and Prusinkiewicz (2005) to visualize canalization models. In our implementation, the top row depicts the L1 layer. Thus, the patterning in the L1 layer, which was extensively described in Smith et al. (2006), appears here in a simplified version in one dimension, within a line of cells (Fig. 3). The interaction between auxin and PIN1 was implemented by using a set of coupled ordinary differential equations that control the production and decay of IAA (indole-3-acetic acid, the naturally occurring auxin) and PIN1, as well as the diffusion and transport of IAA to and from neighbor cells (see the Supplemental Material). As in the phyllotaxis models (Jönsson et al. 2006; Smith et al. 2006), cell interiors are represented as single compartments, and extracellular space is ignored. Cell polarity is determined by the asymmetrical localization of PIN1 at the cell-cell interfaces, which is controlled by a combination of auxin concentration in the adjacent cells (up-the-gradient) and flux across individual interfaces (with-the-flux).

Figure 4 and Supplemental Movie S1 show results of the simulation. The postulated feedback between auxin concentration, flux and PIN1 polarization directs IAA first toward the convergence point in L1, then into the internal tissues, initiating the midvein. In contrast to the original model of Mitchison (1980), the dual polarization model predicts a higher concentration of auxin in the midvein than in the surrounding tissues. PIN1 proteins are oriented basally in the midvein, with lateral polarization toward the midvein in most of the surrounding tissue. As observed experimentally, this lateral polarization is present from the very beginning of vein initiation, as is the high concentration in the central cells of the extending midvein. According to the model, the basal polarization is with-the-flux, whereas the lateral polarization is up-the-gradient. Thus, the complex patterns of polarization results from the cooperation of the two mechanisms.

Apical polarization in inner tissue is predicted by the model and validated by experiment

An unexpected outcome of the model is that it predicts a transient apical (toward the L1) polarization of PIN1 proteins in inner tissue near the emerging midvein (Fig. 4A). This prediction is consistent with the idea that internal cells polarize initially up-the-gradient and switch to with-the-flux polarization afterward, as the auxin concentration increases near the extending midvein. We tested this prediction by further experiments. In tomato, the incipient primordium is specified late, at the Il stage, and midvein formation proceeds rapidly. Early transient events are therefore hard to capture. Nevertheless, extensive live imaging studies indicated the occurrence of apical polarization in inner tissue toward convergence point in the L1 layer (Fig. 5A; Supplemental Figs. S8, S9). In Arabidopsis, incipient primordia are marked by PIN1 expression as early as I3 (Reinhardt et al. 2003b; Heisler et al. 2005), which makes the different stages of vein initiation easier to capture than in tomato. We frequently observed apical polarization of PIN1 toward converging points in the L1 layer of short-day grown Arabidopsis (12 out of 23 cases) (Fig. 5B), followed by basal polarization (Fig. 5C) as predicted by the model (Fig. 4).

\section{PIN1 reacts to ectopic auxin application as predicted by the model}

A key assumption of our model is that auxin is the primary factor controlling PIN1 polarity. To test this experimentally, we investigated the effects of microapplication of auxin on PIN1 polarity in tomato shoot apices. We made use of the fact that in tomato only the I1 site, but not I2, is marked by PIN1 convergence (Fig. 1D,E). This leaves a large uncommitted area of the meristem free for de novo primordium induction through
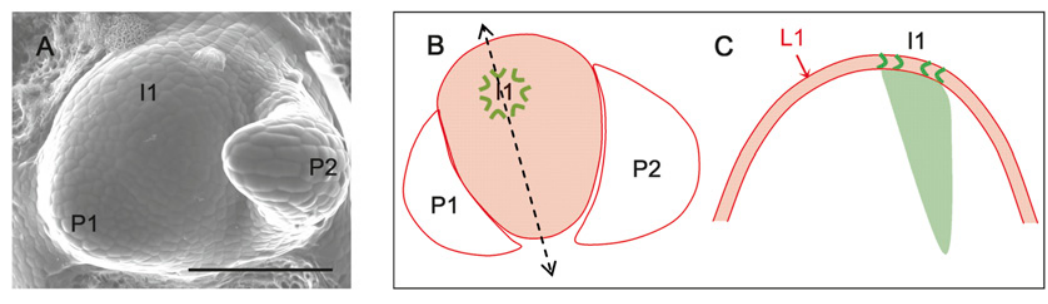

Figure 3. A representation of the shoot apex for simulating midvein formation. (A) Scanning electron micrograph of a vegetative tomato shoot apex. (B) Schematic diagram of the meristem surface with formation of PIN1 convergence point at incipient primordium (I1). (C) Longitudinal section through I1 (the axis of the section is represented by dotted line in $B$ ), with the L1 layer represented as a single line of cells (in red). Patterning begins with Il convergence point formation in the $\mathrm{L} 1$ and extends into inner tissue initiating the midvein (green area). Bar, $100 \mu \mathrm{m}$. 

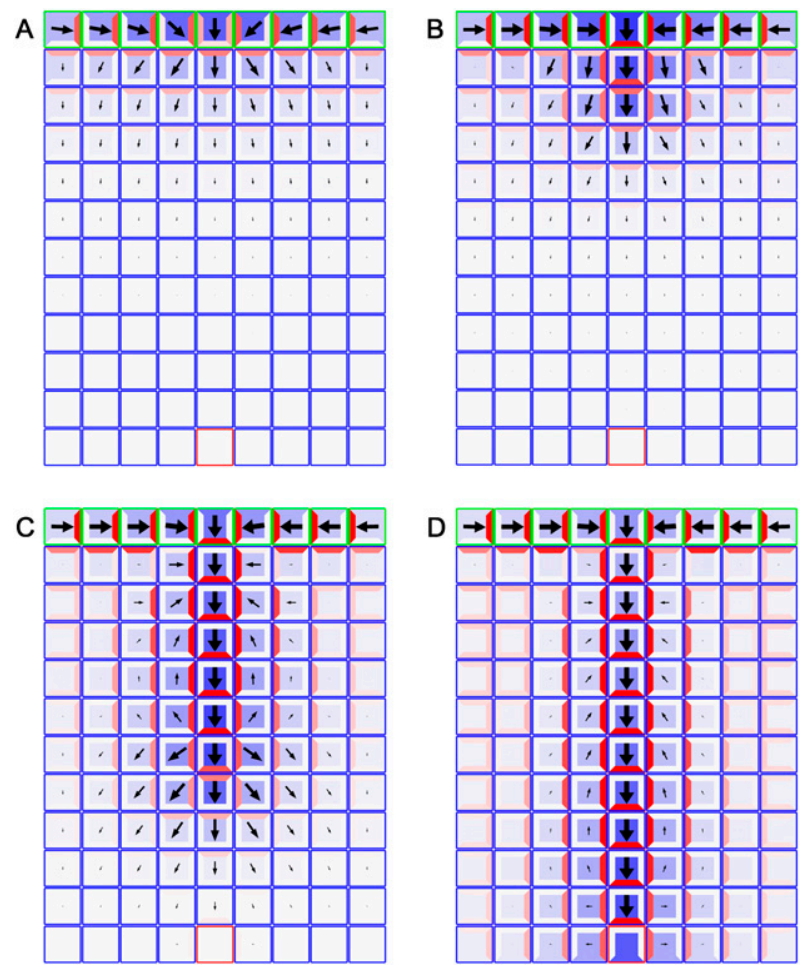

Figure 4. Model of midvein formation on a rectangular grid of cells. Auxin concentration is shown in blue, and the PIN1 allocation is shown in red. The length and width of arrows indicate the magnitude and dominant direction of auxin flux (visualization after Rolland-Lagan and Prusinkiewicz 2005). Auxin is supplied to the top row of cells that represent the L1 layer (outlined in green) in the meristem. A single sink cell in the middle of the last row (outlined in red) represents the existing vasculature of the plant, simulated by an increased rate of IAA decay. (A) Initially, cells in the L1 layer self-organize to specify the site of organ primordium initiation by creating a local auxin maximum, with PIN1 in neighboring cells oriented toward this convergence point. $(B)$ As auxin levels increase, upthe-gradient allocation transitions to with-the-flux allocation, and the convergence point begins to extend into inner tissue. $(C, D)$ As the simulation proceeds, the vein continues to extend until it connects to the existing vasculature. Note that the flux indicators show the combined effects of influx, efflux, and diffusion, whereas the PIN localization only shows the direction of efflux. Simulation times were $3 \mathrm{~h}(A), 5 \mathrm{~h}(B), 9 \mathrm{~h}(C)$, and $12 \mathrm{~h}$ (D).

auxin application. We applied micro-droplets of IAA to this area in AtPIN1:GFP plants and monitored PIN1 expression and polarization at the site of application over time (Fig. 6). After 10-20 h, all 30 control DMSO-treated plants displayed PIN1 polarity in L1 directed toward I1 and away from the I2 position (Fig. 6A). In 14 out of 55 meristems studied, IAA treatment caused PIN1 upregulation and the formation of a convergence point at the site of application, which subsequently led to ectopic primordium induction (Fig. 6, cf. A,C and B,D). These convergence points were always formed before primordium bulging, as confirmed by three-dimensional (3D) reconstructions of longitudinal sections through I2 (Sup- plemental Fig. S10). IAA-treated meristems that displayed a PIN1 expression pattern similar to that of control meristems never formed ectopic primordia. These results are consistent with previous experimental data of Reinhardt et al. (2000), who have shown that microapplication of auxin at I2 induces ectopic primordium formation at the site of application (PIN1 polarization was not observed). Considerable latitude was observed as to where exactly PIN1 convergence points were formed in response to auxin micro-application. Thus in some cases, PIN1 convergence points were formed close to P1 rather than at the normal I2 position (Supplemental Fig. S11).

Optical longitudinal sections through auxin-induced convergence points showed both apical and basal polarization in inner tissues (Fig. 6E,F). At $10 \mathrm{~h}$ after microapplication, both apical and basal polarization was observed. At $20 \mathrm{~h}$, downward polarization was predominant both in the L1 (at the center of the convergence) and in inner tissues. We thus conclude that application of exogenous auxin can influence PIN1 polarity, and the observed changes of PIN1 polarity provide experimental support for a dual polarization mechanism.

\section{Implementation of the model on a cellular template}

The dual polarization model shown in Figure 4 reproduces the experimental observations, such as establishment of a convergence point in the L1, continuous high auxin concentration in the vein, and basal and lateral polarizations in central and peripheral vein cells, respectively. The prediction of transient apical polarization in inner tissue cells was borne out by subsequent experimentation.

To further increase the realism of the model, we developed a cellular representation of a longitudinal section of a real meristem and adapted our model to this template. Simulations showed, however, that the emerging vein was not robustly extending toward the sink that represented the vasculature of the stem. Instead, the midvein seemed to wander due to the irregular geometry of the template. This result is not entirely surprising, since elevated auxin levels in the vein imply a strong auxin gradient in the proximity of the extending vein tip. This gradient overwhelms the weaker global gradient in the tissue toward the sink. Yet the biological data suggest that growing veins are able to find a relatively direct path to the vasculature below, while still maintaining a high auxin concentration. To account for this phenomenon, we introduced the following additional assumption:

6. The existing vasculature guides the developing midvein. This assumption is supported by classical work of Sachs (1981), who demonstrated that existing vasculature attracts initiating veins. The assumption is implemented by giving the PIN1 molecules a propensity to polarize toward the existing differentiated vasculature.

In the simulation model, we established this vein attraction factor by assuming a signal molecule that emanates from the existing vasculature (see the Supplemental Material) and affects the flux-based component of 

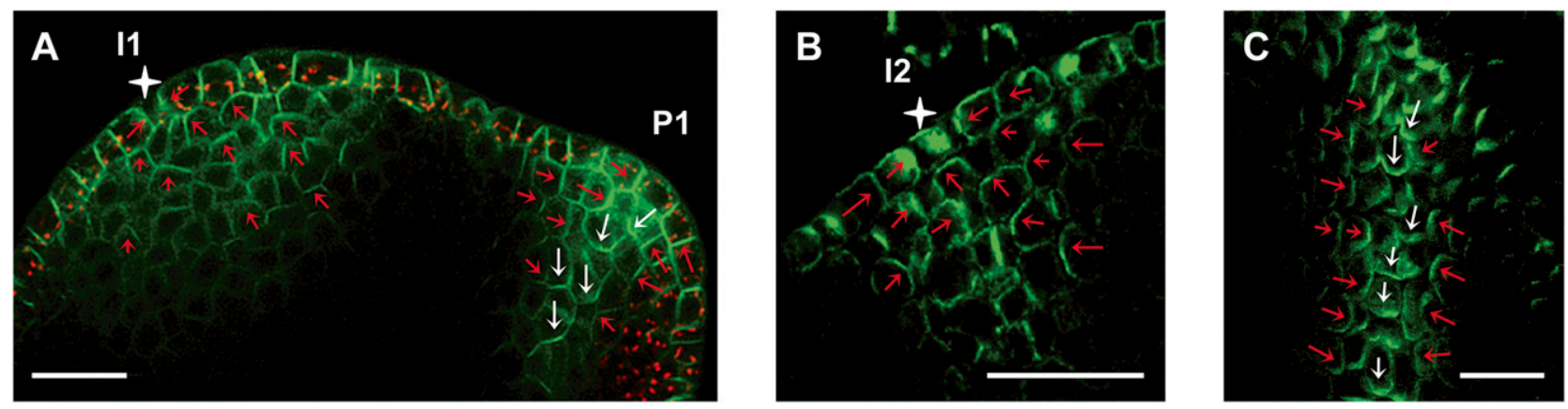

Figure 5. Apical polarization in the subepidermal layers of the shoot apical meristem. $(A)$ Median longitudinal confocal section through a tomato vegetative meristem expressing AtPIN1:GFP (green). Note apical polarization at incipient primordia (I1, red arrows) toward a convergence point in the L1 (white star) and lateral (red arrow) and basipetal (white arrows) polarization in the initiating midvein of bulging primordia (P1). Red signal is plastid autofluorescence in the L1. (B) AtPIN1 immunolocalization in Arabidopsis vegetative shoot apical meristems. Median longitudinal section through I2 position, showing AtPIN1 apical polarization in subepidermal layers, toward a convergence point in the L1 (white star). $(C)$ Longitudinal section through an older Arabidopsis midvein showing basal (white arrows) and lateral (red arrows) AtPIN1 subcellular localization. Bars, $20 \mu \mathrm{m}$.

PIN1 allocation. However, the nature of this factor is not critical, and comparable results were obtained by using a geometric rule to influence PIN polarity (Supplemental Fig. S12). The resulting simulations recreate the observed PIN1 expression and PIN1 localization patterns (Fig. 7; Supplemental Movie S2; cf. Figs. 2, 5), with high auxin concentration maintained in the midvein throughout the simulation. As in the grid model (Fig. 4), the cells in the L1 near the convergence point are initially polarized up-the-gradient toward this point and switch to withthe-flux (downward) polarization as the simulation proceeds.

In the model presented in Figure 7, the initiating midvein is attracted to the vasculature of the closest pre-existing vein. This implies that ablation of this vein should redirect the path of the midvein toward the next closest vein. In tomato vegetative apices, the initiating midvein at I1 connects to the vasculature of P3 (Fig. 1A; Supplemental Fig. S13). Apices expressing AtPIN1:GFP at stage 1 of I1 specification (i.e., before midvein initiation) were selected, and the P3 vein was cut out by making a longitudinal incision with a razor blade. Control meristems were also wounded by making a small cut on the side of the P3 leaf but without touching the vasculature, or by removing $\mathrm{P} 3$ but leaving the portion of $\mathrm{P} 3$ vasculature to which the I1 midvein normally connected (Supplemental Fig. S14). The selected meristems $(n=14)$ were again monitored for PIN1 expression $24 \mathrm{~h}$ later. After P3 vein removal, the I1 midvein was found to preferentially connect to the P2 vasculature (Fig. 8B,D). Control meristems $(n=16)$ showed I1 midvein connecting to P3 vasculature as in untreated samples (Fig. 8A,C; Supplemental Fig. S14). We thus conclude that the existing vasculature indeed has the potential to attract the initiating midvein at I1.

In order to further validate the model, we simulated the effect of manipulation of auxin transport. It has been reported previously that the auxin transport inhibitor NPA can interfere with patterning. When applied to the young leaf, NPA causes a widening of the veins (Mattsson et al. 2003), while treating vegetative shoot apical meristems causes a cessation of leaf initiation and the formation of pin-like structures (Reinhardt et al. 2000). Reducing transport in the model produced wider veins (Fig. 9A,B), and when transport was severely reduced, formation of convergence points in the L1 was lost. Moreover, basal PIN1 polarization in inner tissues was not visible anymore, but, instead, the model predicted apical up-the-gradient polarization toward the L1 (Fig. 9C). In order to verify our model predictions, we checked PIN1 expression and polarization patterns in NPA-pins, and observed prominent apical polarization in a wide domain of inner tissue cells (Fig. 9D). Thus, the model faithfully recapitulates the effect of manipulation of auxin transport.

\section{Discussion}

The process of leaf positioning begins with the convergent localization of PIN1 proteins and the formation of an auxin maximum at the location of the incipient leaf primordium. The intensity of the DR 5 reporter increases continuously with no indication of a transient dip. This auxin maximum is likely due to both polar auxin transport toward the convergence point in L1 and onset of local auxin production at the site of the future primordium (Zhao 2008). Subsequently, cells at the convergence point in the L1 acquire basal PIN1 polarization and pump auxin into inner layers. PIN1 turns on in these layers in a triangular expression domain, which gradually resolves into a narrow canal. This canal is characterized by high auxin concentration and basal PIN1 polarization accompanied by lateral polarization in the adjacent cells.

Mechanistically, the initiation of the leaf and the midvein involves auxin gradients that are set up through a feedback loop between auxin and PIN1. Leaf development requires the creation of regularly spaced spots at the meristem surface, which subsequently extend into the interior cell layers as continuous strands. A mechanism based on up-the-gradient polarization of PIN1 robustly 

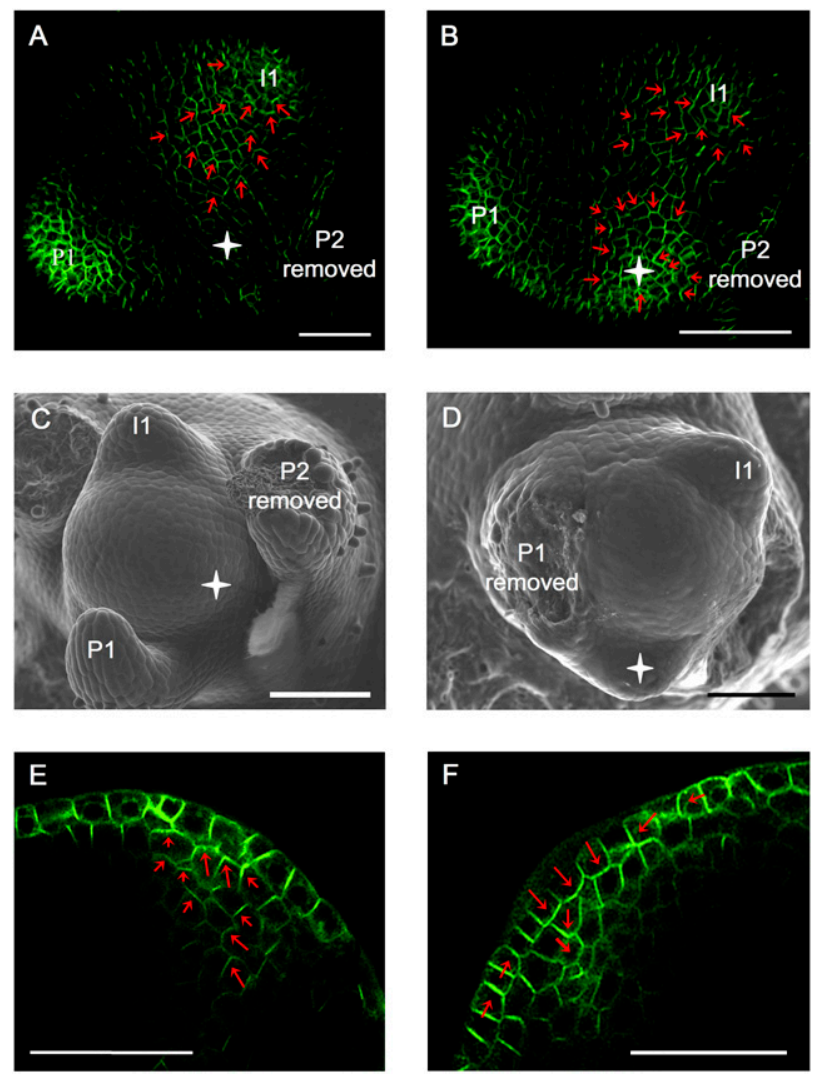

Figure 6. PIN1 reacts to ectopic auxin application. $(A, B)$ Maximal projection of transversal confocal scans of wild-type tomato meristems expressing AtPIN1:GFP. (A) Control meristem $20 \mathrm{~h}$ after microapplication of DMSO only, showing a normal expression pattern with AtPIN1:GFP polarizing toward I1. Extending from this position is a PIN1 expression domain with polarity clearly away from I2 and toward I1. $(B)$ Comparable meristem, $20 \mathrm{~h}$ after microapplication of IAA in DMSO. A convergence point is visible at Il as well as at the site of microapplication. (Red arrows) AtPIN1:GFP polarity. $(C, D)$ Scanning electron microscope pictures of the same meristems as shown in panels $A$ and $B$, respectively, $50 \mathrm{~h}$ after treatment. (D) Note ectopic primordium formation at the site of IAA microapplication (white star). $(E, F)$ Optical longitudinal confocal section through IAA-induced PIN1 convergence point, $10 \mathrm{~h}(E)$ and $20 \mathrm{~h}(F)$ after microapplication. Note the apical $(E)$ followed by basal $(F)$ polarization of AtPIN1:GFP in inner tissues. Bars, 50 $\mu \mathrm{m}$.

produces peaks of high auxin concentration that are spaced in correct phyllotactic patterns. On the other hand, with-the-flux polarization is well suited to produce continuous strands of differentiated tissue, although the canalization model's prediction that the concentration of auxin in the developing vein will be lower than in the surrounding tissue is contradicted by experimental data, which show that expression of auxin-responsive markers in the vein is high.

Since phyllotaxis and midvein initiation are overlapping processes, the question arises as to how the two different PIN1 polarization mechanisms may work together. We propose a model according to which these mechanisms operate simultaneously. According to this model, polarization toward the convergence point (upthe-gradient) dominates in the L1, but cells at the convergence point switch to basal polarization, consistent with with-the-flux polarization, thus preventing unlimited accumulation of auxin in the emerging primordia. Both polarization mechanisms also cooperate to initiate the midvein, as cells in the initiating midvein are oriented basally (with-the-flux), directing auxin outflux from the primordia, while neighboring cells are polarized laterally toward the center (up-the-gradient), focusing the midvein to a narrow strand of cells.

The models that rely on a single polarization mechanism, be it up-the-gradient (Merks et al. 2007) or withthe-flux (Stoma et al. 2008), require a transient decrease in auxin concentration at the convergence point during the initial stage of midvein formation. In contrast, the patterns of PIN1 polarization and DR5 expression produced by the dual polarization model are in agreement with all the available experimental data. Given that both up-the-gradient and with-the-flux models are able to explain portions of the available data, it seemed natural to us to consider the dual polarization model as a combination of the two. From this perspective, neither single model is "wrong," but represents an aspect of a more complex reality.

Models should not only catalog existing data but also make predictions that can be tested experimentally. The
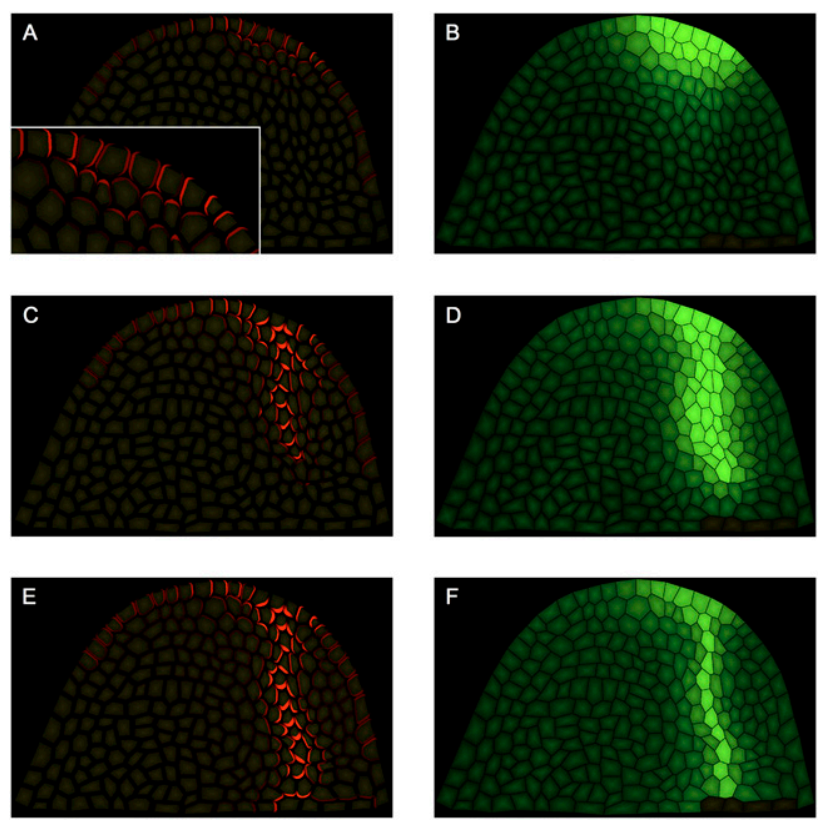

Figure 7. Simulation model of midvein formation on a cellular meristem template. $(A, C, E)$ PIN1 protein localization shown in red at different time points of the simulation. $(B, D, F)$ IAA concentration shown in green at the same time points of the simulation. Dark cells at the bottom right are sinks for auxin and represent pre-existing vasculature. $(A$, inset $)$ The closeup shows apical polarization of PIN1 in the initial stages of midvein formation. Simulation times were $2 \mathrm{~h}(A, B), 5 \mathrm{~h}(C, D)$, and $12 \mathrm{~h}$ $(E, F)$. 

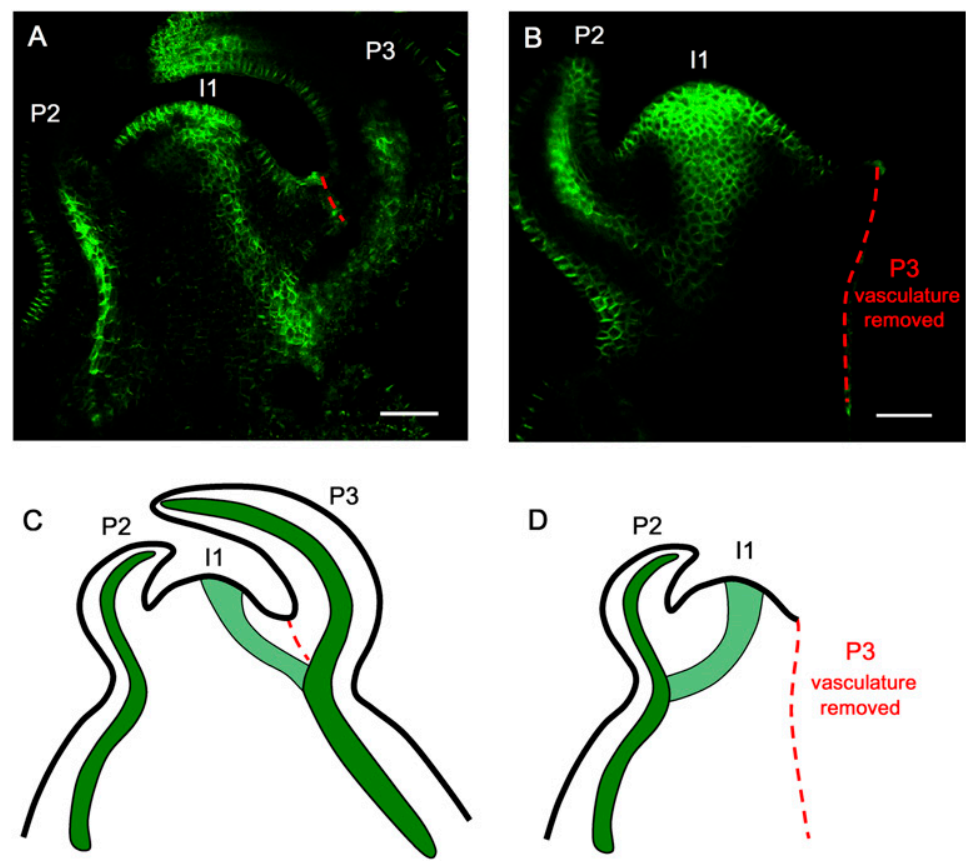

Figure 8. The existing vasculature guides the initiating midvein. (A) Control meristem showing the initiating midvein at I1 connecting to the P3 vein. As a control for wounding effects, a partial incision was made that did not sever the $\mathrm{P} 3$ vasculature (red dashed line). (B) In the absence of $\mathrm{P} 3$ vasculature, the initiating midvein preferentially connects to the P2 vein. P3 and its derived vasculature were removed with a razor blade before I1 midvein initiation (stage 1 of I1 specification) (see Supplemental Fig. S3) (red dashed line indicates the cut). $(A, B)$ Maximal projection of longitudinal confocal scans of wild-type tomato meristems expressing AtPIN1:GFP. $(C, D)$ Schematic representations of $A$ and $B .(\mathrm{P})$ Bulging leaf primordia with $\mathrm{P} 1$ representing the youngest primordium; (I1) incipient primordium. See Supplemental Figure S14 for an additional control experiment. Bars, $50 \mu \mathrm{m}$. dual polarization model predicted transient apical polarization at the tip of the midvein that was confirmed by subsequent experiments. It is a good example of how mathematical models can guide experimental work. The model also provides an answer to an interesting question in pattern formation; namely, how a patterning mechanism can first create regularly spaced spots and then extend them into continuous strands. Thus, the model provides a unified view of phyllotaxis and vein initiation.

Our simulations on a realistic cellular template suggest that the existing vasculature guides the emerging midvein. In support of this notion, we show that the path of the vein can be experimentally redirected by ablation of portions of the existing vasculature (Fig. 8). We postulate that vein guidance is accomplished by a factor that emanates from the stem vasculature. This signal may also play a role in phyllotactic patterning. In recent years, the dominating view has been that leaf positioning takes place exclusively in the L1 layer of the meristem (Reinhardt et al. 2003b; Heisler et al. 2005; de Reuille et al. 2006; Jönsson et al. 2006; Smith et al. 2006), but according to an alternative view, the pre-existing veins also play a role; i.e., patterning information flows into the meristem from below (Esau 1965; Larson 1975; Kang et al. 2003). In future experiments we intend to investigate whether the postulated signal from the vasculature may increase the robustness of phyllotactic patterning.

\section{Materials and methods}

\section{Plant material and growth conditions}

AtPIN1::AtPIN1:GFP-expressing tomato plants were generated as follows: The previously described AtPIN1::PIN1:GFP construct (Benkova et al. 2003) was transformed into wild-type tomato (L. esculentum cV Moneymaker) plants, using Agrobacterium-mediated leaf transformation and subsequent regeneration of plants from callus. In brief, etiolated cotyledons $(10 \mathrm{~d}$ after germination) were cut and laid out on plates with conditioning medium $(4.4 \mathrm{~g} / \mathrm{L}$ Murashige and Skoog + minimal organics MSMO, $30 \mathrm{~g} / \mathrm{L}$ sucrose, $6 \mathrm{~g} / \mathrm{L}$ agar at $\mathrm{pH} 5.8$ supplemented with $0.1 \mathrm{mg} / \mathrm{L}$ 6-benzyl amino purin and $1 \mathrm{mg} / \mathrm{L}$ 1-naphtalene acetic acid) and kept for two more days in the dark at $22^{\circ} \mathrm{C}$. Agrobacterium with the plasmid were grown in bacteria growth medium $(10 \mathrm{~g} / \mathrm{L}$ yeast-extract, $10 \mathrm{~g} / \mathrm{L}$ bacto-peptone, $5 \mathrm{~g} / \mathrm{L} \mathrm{NaCl}$, supplemented with $0.2 \mathrm{mM}$ acetosyringone and antibiotics) and dropped onto the cotyledons. Cocultivation was done at $22^{\circ} \mathrm{C}$ in the dark for $2 \mathrm{~d}$. The leaves were transferred to selection medium $(4.4 \mathrm{~g} / \mathrm{L}$ Murashige and Skoog + minimal organics, 9.6 $\mathrm{g} / \mathrm{L}$ thiamine, $1.0 \mathrm{mg} / \mathrm{L}$ nicotinic acid, $1.0 \mathrm{mg} / \mathrm{L}$ pyridoxinic acid, $30 \mathrm{~g} / \mathrm{L}$ sucrose, $6 \mathrm{~g} / \mathrm{L}$ agar at $\mathrm{pH} 5.8$ supplemented with 1 $\mathrm{mg} / \mathrm{L}$ trans-zeatin, $250 \mathrm{mg} / \mathrm{L}$ timentin and kanamycin; for concentrations, see the next sentence). Cultivation was in the light at $22^{\circ} \mathrm{C}$ in glass jars with increasing kanamycin concentrations: $3 \mathrm{~d}$ at $35 \mathrm{mg} / \mathrm{L}, 1$ wk at $35 \mathrm{mg} / \mathrm{L}, 2 \times 1$ wk at $50 \mathrm{mg} / \mathrm{L}$, and $2 \times 1$ wk at $100 \mathrm{mg} / \mathrm{L}$. Then the shoots were transferred to rooting medium $(4.4 \mathrm{~g} / \mathrm{L}$ Murashige and Skoog + minimal organics, $9.6 \mathrm{~g} / \mathrm{L}$ thiamine, $1.0 \mathrm{mg} / \mathrm{L}$ nicotinic acid, $1.0 \mathrm{mg} / \mathrm{L}$ pyridoxinic acid, $30 \mathrm{~g} / \mathrm{L}$ sucrose at $\mathrm{pH} 5.8,6 \mathrm{~g} / \mathrm{L}$ agar, supplemented with $0.1 \mathrm{mg} / \mathrm{L}$ indole acetic acid and $500 \mathrm{mg} / \mathrm{L}$ vancomycin). After rooting, plants were transferred to soil. Tomato lines from the $\mathrm{T} 1$ containing the construct were selected on kanamycin. Three homozygous lines were then selected by looking at the progeny.

Wild-type (Lycopersicon esculentum cv Moneymaker) and AtPIN1::AtPIN1:GFP-expressing tomato plants were grown on soil under long photoperiod ( $16 \mathrm{~h}$ of light, $65 \%-80 \%$ humidity, $20^{\circ} \mathrm{C}-22^{\circ} \mathrm{C}$ day temperature, irradiance $60 \mu \mathrm{Em}^{-2} \mathrm{~s}^{-1}$ ). For in vitro culture, shoot apices were dissected and transferred to MS medium containing $0.01 \mu \mathrm{M}$ gibberellic acid A3 (Fluka) and 0.01 $\mu \mathrm{M}$ kinetin (Sigma) (Fleming et al. 1997). For auxin transport inhibitor treatment, N-1-naphthylphthalamic acid (NPA, Interchim; $10 \mathrm{mM}$ stock solution in DMSO) and preservative for plant 

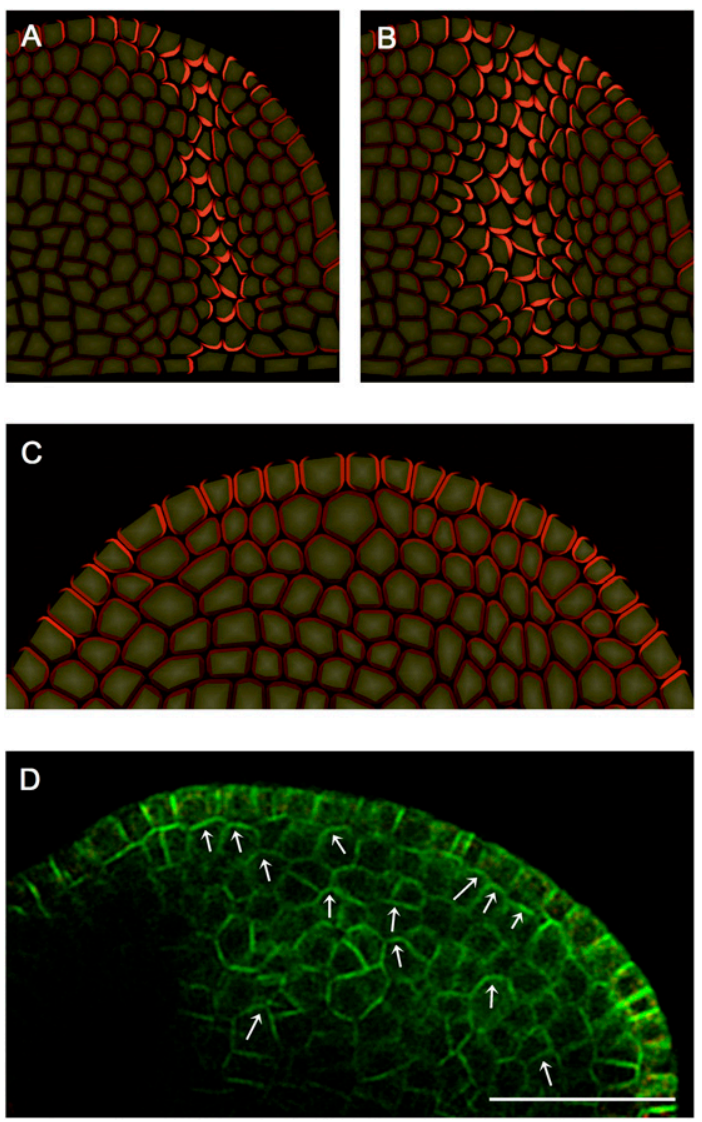

Figure 9. Effects of reduced auxin transport. (A) Control simulation with the same parameters as Figure 7. (B) Simulation with a $60 \%$ reduction in active auxin transport. Note the widening of the vein. Red indicates PIN1 localization. $(C)$ Simulation of strongly reduced active auxin transport. PIN1 (red) is expressed in inner tissues due to auxin diffusion from the L1 layer. Polarization is preferentially apical toward the L1. $(D)$ Median longitudinal confocal section through a tomato grown on $10 \mu \mathrm{M}$ NPA. AtPIN-GFP is shown in green. Note apical polarization (white arrows) toward the L1 layer in the inner tissue, as predicted by the model. Bar, $50 \mu \mathrm{m}$.

tissue culture (PPM, Plant Cell Technology) were added to the MS medium ( $1 \mu \mathrm{L} / \mathrm{mL}$ each). The base of the apices was trimmed and apices were transferred to new NPA plates once every $4 \mathrm{~d}$. NPA tomato pins were cultured for $8 \mathrm{~d}$ on NPA media before confocal observation. All Arabidopsis thaliana lines were in the Columbia background and were grown on soil under a short photoperiod $\left(8 \mathrm{~h}\right.$ light, $65 \%-80 \%$ humidity, $20^{\circ} \mathrm{C}-22^{\circ} \mathrm{C}$ day temperature, irradiance $100-150 \mu \mathrm{Em}^{-2} \mathrm{~s}^{-1}$ ).

\section{Isolation of tomato PIN1 homolog}

Total RNA was isolated from tomato vegetative apices (including P1-P6), as described by Reinhardt et al. (1998). After reverse transcription, PCR amplification was performed using two degenerate primers (sense primer 5 '-GAYXTXCAYATGTTYGTN TGG-3' and antisense primer 5'-CATXCCRAADATXACNG CNGT-3') to conserved sequences in the coding region of Arabidopsis PIN1. A DNA fragment with the expected length of $\sim 600$ base pairs (bp) was obtained that showed high homology with Arabidopsis PIN1. Internal primers were designed and a fragment of $165 \mathrm{bp}$ was cloned and used as a probe to screen a phage cDNA library derived from tomato vegetative meristems (including P1 only). Several positive clones were isolated, of which four were sequenced and confirmed to be identical to the probe used. One of the sequences of tomato covered part of the hydrophilic loop and the hydrophobic domain in the $\mathrm{C}$ terminus. The tomato PIN1 protein exhibited an amino acid similarity of $60 \%$ with Arabidopsis PIN1.

\section{Anti-tomato PIN1 antibodies}

Based on the partial cDNA sequence of tomato PIN1, two peptide sequences (GHDEESGVAGFGKGN and HPKDDEFGREEFTFG) were selected in the cytosolic loop domain and used to raise antibodies in rabbits that were affinity-purified (made by Eurogentec).

\section{Microapplications}

Microapplication experiments were carried out as described in Reinhardt et al. (2000). For microapplication on tomato, vegetative apices expressing AtPIN1::AtPIN1:GFP plants were dissected, leaving only P1 and P2 leaf primordia at the meristem. After transfer to MS media, a microdroplet of IAA-containing lanolin ( $\sim 0.02 \mathrm{~nL}$ containing 1 pmol IAA; $0.5 \%$ DMSO) was applied at the I2 position. As discussed in Reinhardt et al. (2000), the applied auxin concentrations are higher than what is assumed to be the cellular concentration. However, compared with experiments in which an organ is immersed in auxin, the volume of the droplet is small relative to the shoot apex to which it is applied. Also, auxin is a lipophilic molecule that has to move out of the lipophilic lanolin paste into the aqueous cell wall and from there through the plasma membrane. Thus, we assume the applied concentrations are physiologically relevant. For control plants, DMSO-containing lanolin paste was used. After $10-20 \mathrm{~h}$ of microapplication, the subcellular localization of AtPIN1:GFP at the meristem surface was visualized by confocal microscopy. Primordia outgrowth was assessed after 50-60 h of treatment, by scanning electron microscopy.

\section{P3 vein ablation}

Tomato vegetative apices expressing AtPIN1::AtPIN1:GFP were dissected leaving P1-P3 at the meristem. For each apex, AtPIN1:GFP polarity at the meristem surface was analyzed by confocal microscopy (transversal sections), and those that were at stage 1 of incipient primordia (I1) specification (Supplemental Fig. S3) were selected. P3 vasculature was removed by making a longitudinal incision with a razor blade (Fig. 8D). Control meristems were also wounded by making a small cut on the side of the P3 leaf but without touching the vasculature, or by removing $\mathrm{P} 3$ but leaving the portion of $\mathrm{P} 3$ vasculature to which the I1 midvein normally connects (Fig. 8C and Supplemental Fig. S14B, respectively). The meristems then were transferred to MS media and the midvein initiation at I1 was monitored $24 \mathrm{~h}$ later using confocal microscopy (longitudinal sections). When necessary, meristems were cut longitudinally with a razor blade in order to access internal tissues and reveal midvein connection to existing veins.

\section{Immunolocalization}

Immunolocalizations were done on sections from wax-embedded plant material and performed as described in Bainbridge et al. (2008). For immunodetection of tomato PIN1 and Arabidopsis 
PIN1, 2- to 3-wk-old wild-type tomato and 5-wk-old Arabidopsis plants were used, respectively. Anti-tomato PIN1 antibodies were diluted 1:50 and anti-Arabidopsis PIN1 (Benkova et al. 2003) were diluted 1:400. Alexa Fluor 488-conjugated goat secondary antibodies were used (1 in 300; Molecular Probes). For control slides, samples were incubated with preimmune antiserum (one out of 50) and/or secondary antibodies only.

\section{Microscopy}

Confocal analysis of immunolocalizations was carried out using a Leica inverted confocal laser-scanning microscope (DMIRE2) with water immersion $20 \times$ or $63 \times$ objectives. Excitation was at $488 \mathrm{~nm}$ at $20 \%$ of full power and collection between 505 and 545 $\mathrm{nm}$. Live imaging of tomato plants expressing AtPIN1:GFP was performed using a Leica upright confocal laser-scanning microscope (DMRXE7) equipped with a long-working-distance water immersion objective (-L20/0.5 U-V-I). In order to get access to the vegetative meristem, the first five to six leaf primordia of 2-wkold plants were removed, leaving only the two youngest primordia (P1 and P2) at the shoot apex. The apices were immediately transferred to MS media and covered with water for confocal imaging. Plants were left under water for scanning time only $(\sim 5$ min). Excitation was set at $488 \mathrm{~nm}$ with $30 \%$ laser power for transversal sections and $50 \%$ for longitudinal sections. The collection wavelengths were 505-550 nm for GFP and 620-690 nm for plastid autofluorescence. Scanning speed was set at 200 or $400 \mathrm{~Hz}$ with line average of 2-4 and $512 \times 512$-pixel frames. The pinhole was set at $1 \mathrm{AE}$. For $3 \mathrm{D}$ reconstruction and maximum projection, stacks of $\sim 40$ sections spaced $1.5-2 \mu \mathrm{m}$ apart were collected. 3D reconstruction was performed using Imaris 5.7 software (Bitplane AG). The subcellular localization of AtPIN1:GFP was assessed by identifying arcs of GFP signal corresponding to AtPIN1:GFP protein within cell corners as described in Heisler et al. (2005). For each meristem, AtPIN1:GFP polarity at the meristem surface was analyzed by looking at both maximum $Z$ stack projection and $3 \mathrm{D}$ reconstruction, which by manipulating the angle of visualization gave a clear indication of the subcellular polarity. Additionally, in order to highlight AtPIN1:GFP subcellular polarity, confocal images were sequentially processed with a blurring filter (to decrease noise) followed by a sharpening filter (linear filters). To assess AtPIN1:GFP subcellular localization in inner tissue in Figures 5A and 6, E and F, apices were manually tilted so that optical scanning was done in the longitudinal axis. The orientation of the section plane and the position of single scans were always confirmed by $3 \mathrm{D}$ reconstruction (Supplemental Fig. S10). For scanning electron microscopic analysis, freshly dissected tissue was viewed with a S3500N variable pressure scanning electron microscope (Hitachi) equipped with a cool stage.

\section{Computer programming}

The cellular longitudinal section model of the shoot apex was created using the Merrysim software (de Reuille et al. 2006) and loaded into a VV (Smith et al. 2003) mesh with the same cellular structure that was used for the phyllotaxis model by Smith et al. (2006). The simulations on rectangular grids of cells were derived from simulations provided by Rolland-Lagan and Prusinkiewicz (2005).

\section{Acknowledgments}

We thank C. Smith and A. Runions for help with simulations; Y. Kremp, Y. Chatton, and B. Zarda for help with imaging; C. Brancato for tomato transformation; R. Mazza for the isolation of the tomato PIN1 homolog; D. Reinhardt, J. Friml, P. Barbier de Reuille, S. Guyomarc'h, and U. Klahre for critically reading the manuscript; and R. Alder and C. Ball for expert plant care. This work was supported by Swiss National Science Foundation grant 3100A0-105807 to C.K.; SystemsX.ch project "Plant Growth in a Changing Environment"; the Natural Sciences and Engineering Research Council of Canada Discovery Grant RGPIN 1300842008 to P.P.; and a University of Calgary Ruby doctoral scholarship to R.S.S.

\section{References}

Avsian-Kretchmer, O., Cheng, J.C., Chen, L.J., Moctezuma, E., and Sung, Z.R. 2002. Indole acetic acid distribution coincides with vascular differentiation pattern during Arabidopsis leaf ontogeny. Plant Physiol. 130: 199-209.

Baima, S., Nobili, F., Sessa, G., Lucchetti, S., Ruberti, I., and Morelli, G. 1995. The expression of the Athb-8 homeobox gene is restricted to provascular cells in Arabidopsis thaliana. Development 121: 4171-4182.

Bainbridge, K., Guyomarc'h, S.,, Bayer, E., Swarup, R., Bennett, M., Mandel, T., and Kuhlemeier, C. 2008. Auxin influx carriers stabilize phyllotactic patterning. Genes \& Dev. 22: 810-823.

Benkova, E., Michniewicz, M., Sauer, M., Teichmann, T., Seifertova, D., Jurgens, G., and Friml, J. 2003. Local, effluxdependent auxin gradients as a common module for plant organ formation. Cell 115: 591-602.

Couder, Y., Pauchard, L., Allain, C., Adda-Bedia, M., and Douady, S. 2002. The leaf venation as formed in a tensorial field. Eur. Phys. J. B 28: 135-138.

de Reuille, P.B., Bohn-Courseau, I., Ljung, K., Morin, H., Carraro, N., Godin, C., and Traas, J. 2006. Computer simulations reveal properties of the cell-cell signaling network at the shoot apex in Arabidopsis. Proc. Natl. Acad. Sci. 103: 1627-1632.

Dupuy, L., Mackenzie, J., Rudge, T., and Haseloff, J. 2008. A system for modelling cell-cell interactions during plant morphogenesis. Ann. Bot. (Lond.) 101: 1255-1265.

Esau, K. 1965. Plant anatomy. Wiley, New York.

Fleming, A.J., McQueenMason, S., Mandel, T., and Kuhlemeier, C. 1997. Induction of leaf primordia by the cell wall protein expansion. Science 276: 1415-1418.

Green, P.B. 1980. Organogenesis-A biophysical view. Annu. Rev. Plant Physiol. Plant Mol. Biol. 31: 51-82.

Heisler, M.G., Ohno, C., Das, P., Sieber, P., Reddy, G.V., Long, J.A., and Meyerowitz, E.M. 2005. Patterns of auxin transport and gene expression during primordium development revealed by live imaging of the Arabidopsis inflorescence meristem. Curr. Biol. 15: 1899-1911.

Hellendoorn, P. and Lindenmayer, A. 1974. Phyllotaxis in Bryophyllum tubiflorum-Morphogenetic studies and computer simulations. Acta Botanica Neerlandica 23: 473492.

Jönsson, H., Heisler, M.G., Shapiro, B.E., Meyerowitz, E.M., and Mjolsness, E. 2006. An auxin-driven polarized transport model for phyllotaxis. Proc. Natl. Acad. Sci. 103: 1633-1638.

Kang, J. and Dengler, N. 2004. Vein pattern development in adult leaves of Arabidopsis thaliana. Int. J. Plant Sci. 165: 231-242.

Kang, J., Tang, J., Donnelly, P., and Dengler, N. 2003. Primary vascular pattern and expression of ATHB-8 in shoots of Arabidopsis. New Phytol. 158: 443-454.

Kramer, E.M. 2004. PIN and AUX/LAX proteins: Their role in auxin accumulation. Trends Plant Sci. 9: 578-582.

Kramer, E.M. 2008. Computer models of auxin transport: A review and commentary. J. Exp. Bot. 59: 45-53. 
Larson, P.R. 1975. Development and organization of primary vascular system in Populus deltoides according to phyllotaxy. Am. J. Bot. 62: 1084-1099.

Mattsson, J., Sung, Z.R., and Berleth, T. 1999. Responses of plant vascular systems to auxin transport inhibition. Development 126: 2979-2991.

Mattsson, J., Ckurshumova, W., and Berleth, T. 2003. Auxin signaling in Arabidopsis leaf vascular development. Plant Physiol. 131: 1327-1339.

Meinhardt, H. 1982. Models of biological pattern formation. Academic Press, New York.

Merks, R.M.H., Van de Peer, Y., Inze, D., and Beemster, G.T.S. 2007. Canalization without flux sensors: A traveling-wave hypothesis. Trends Plant Sci. 12: 384-390.

Mitchison, G.J. 1980. Model for vein formation in higher-plants. Proc. R. Soc. Lond. B Biol. Sci. 207: 79-109.

Mitchison, G.J. 1981. The polar transport of auxin and vein patterns in plants. Philos. Trans. R. Soc. Lond. B Biol. Sci. 295: 461-471.

Reinhardt, D., Wittwer, F., Mandel, T., and Kuhlemeier, C. 1998. Localized upregulation of a new expansin gene predicts the site of leaf formation in the tomato meristem. Plant Cell 10: 1427-1437.

Reinhardt, D., Mandel, T., and Kuhlemeier, C. 2000. Auxin regulates the initiation and radial position of plant lateral organs. Plant Cell 12: 507-518.

Reinhardt, D., Frenz, M., Mandel, T., and Kuhlemeier, C. 2003a. Microsurgical and laser ablation analysis of interactions between the zones and layers of the tomato shoot apical meristern. Development 130: 4073-4083.

Reinhardt, D., Pesce, E.R., Stieger, P., Mandel, T., Baltensperger, K., Bennett, M., Traas, J., Friml, J., and Kuhlemeier, C. 2003b. Regulation of phyllotaxis by polar auxin transport. Nature 426: $255-260$.

Rinne, P.L.H. and van der Schoot, C. 1998. Symplasmic fields in the tunica of the shoot apical meristem coordinate morphogenetic events. Development 125: 1477-1485.

Rolland-Lagan, A.G. and Prusinkiewicz, P. 2005. Reviewing models of auxin canalization in the context of leaf vein pattern formation in Arabidopsis. Plant J. 44: 854-865.

Runions, A., Fuhrer, M., Lane, B., Federl, P., Rolland-Lagan, A.G., and Prusinkiewicz, P. 2005. Modeling and visualization of leaf venation patterns. ACM Trans. Graph. 24: 702-711.

Sachs, T. 1969. Polarity and induction of organized vascular tissues. Ann. Bot. (Lond.) 33: 263.

Sachs, T. 1981. The control of the patterned differentiation of vascular tissues. Adv. Bot. Res. 9: 151-262.

Savaldi-Goldstein, S., Peto, C., and Chory, J. 2007. The epidermis both drives and restricts plant shoot growth. Nature 446: 199-202.

Scarpella, E., Francis, P., and Berleth, T. 2004. Stage-specific markers define early steps of procambium development in Arabidopsis leaves and correlate termination of vein formation with mesophyll differentiation. Development 131: 3445-3455.

Scarpella, E., Marcos, D., Friml, J., and Berleth, T. 2006. Control of leaf vascular patterning by polar auxin transport. Genes \& Dev. 20: 1015-1027.

Smith, C., Prusinkiewicz, P., and Samavati, F. 2003. Local specification of surface subdivision algorhithms. Lecture Notes in Computer Science 3062: 313-327.

Smith, R.S., Guyomarc'h, S., Mandel, T., Reinhardt, D., Kuhlemeier, C., and Prusinkiewicz, P. 2006. A plausible model of phyllotaxis. Proc. Natl. Acad. Sci. 103: 1301-1306.

Stoma, S., Lucas, M., Chopard, J., Schaedel, J., Traas, J., and Godin, C. 2008. Flux-based transport enhancement as a plau- sible unifying mechanism for auxin transport in meristem development. PLoS Comput. Biol. 4: e1000207. doi:10.1371/ journal.pcbi.1000207.

Uggla, C., Moritz, T., Sandberg, G., and Sundberg, B. 1996. Auxin as a positional signal in pattern formation in plants. Proc. Natl. Acad. Sci. 93: 9282-9286.

Vieten, A., Vanneste, S., Wisniewska, J., Benkova, E., Benjamins, R., Beeckman, T., Luschnig, C., and Friml, J. 2005. Functional redundancy of PIN proteins is accompanied by auxin dependent cross-regulation of PIN expression. Development 132: 4521-4531.

Vroemen, C.W., Langeveld, S., Mayer, U., Ripper, G., Jurgens, G., Van Kammen, A., and De Vries, S.C. 1996. Pattern formation in the Arabidopsis embryo revealed by position-specific lipid transfer protein gene expression. Plant Cell 8: 783-791.

Zhao, Y. 2008. The role of local biosynthesis of auxin and cytokinin in plant development. Curr. Opin. Plant Biol. 11: 16-22. 


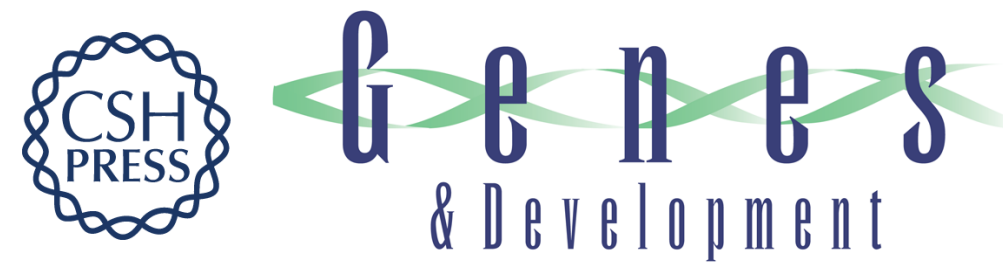

\section{Integration of transport-based models for phyllotaxis and midvein formation}

Emmanuelle M. Bayer, Richard S. Smith, Therese Mandel, et al.

Genes Dev. 2009, 23:

Access the most recent version at doi:10.1101/gad.497009

\section{Supplemental http://genesdev.cshlp.org/content/suppl/2009/02/02/23.3.373.DC1 Material}

References This article cites 41 articles, 18 of which can be accessed free at: http://genesdev.cshlp.org/content/23/3/373.full.html\#ref-list-1

\section{License}

Email Alerting

Service

Receive free email alerts when new articles cite this article - sign up in the box at the top right corner of the article or click here.

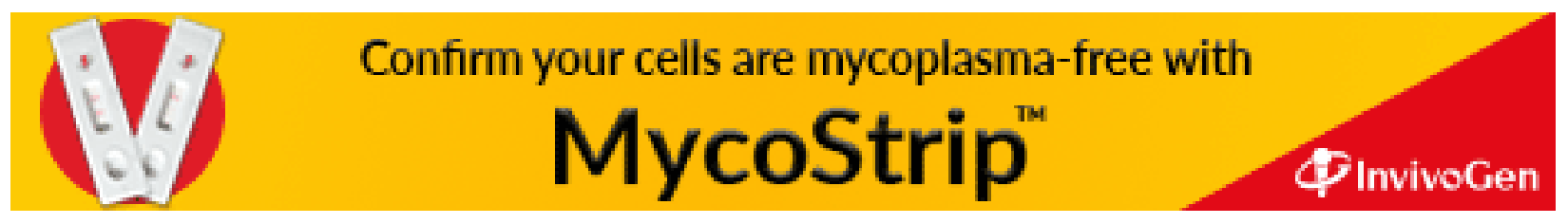

